\title{
Cartografías de la imaginación o los fulgores de la crítica
}

\author{
Por Ariel Castillo Mier ${ }^{1}$
}

Universidad del Atlántico

Santos García, Emiro. (2003). Cartografías de la imaginación. Ensayos sobre literatura hispanoamericana y del Caribe. Cartagena: Editorial Universitaria-Universidad de Cartagena, 138p.

¿Qué se le puede pedir a la crítica? Luz, más luz sobre la tierra natal de la página: que ilumine los territorios de los textos, que guíe al lector para pasar del piso inicial de la comprensión a los niveles más altos, revelando lo oculto y generando una apertura mental, emocional y sentimental, al punto de permitirle apropiarse de una serie de nociones inéditas, precisar entrevisiones y sugerencias sutiles y entrar de lleno e instalarse en el reino de la significación, en la riqueza inmanente de las obras. Me atrevo a afirmar que tales presupuestos se cumplen a cabalidad en es-

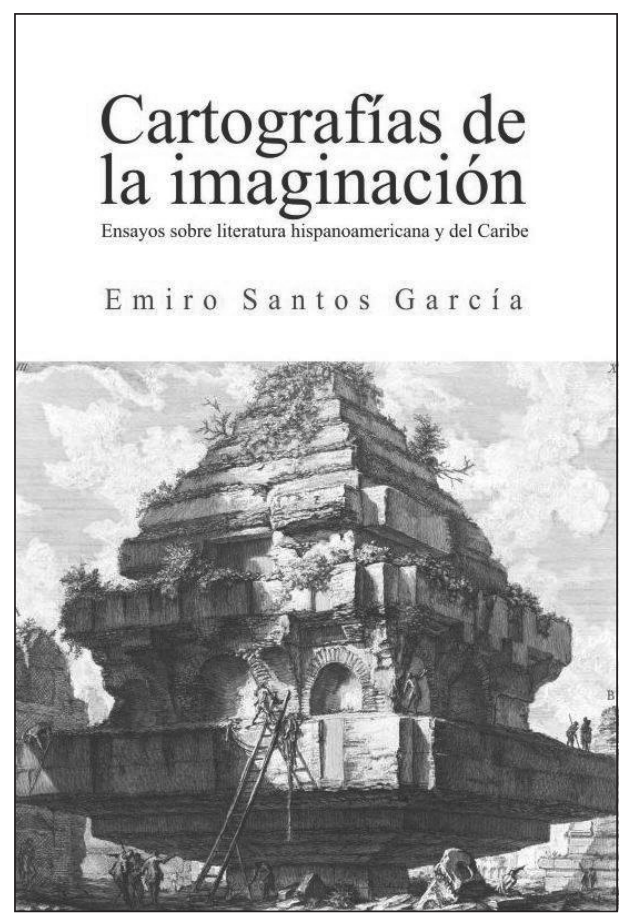
tas Cartografías de la imaginación, de Emiro Santos García, ensayo casi sin antecedentes, no sólo en el Caribe colombiano, sino en las letras nacionales.

\footnotetext{
${ }^{1}$ Profesor de la Universidad del Atlántico. Licenciado en Filología en Idiomas de la Universidad del Atlántico, Magíster en Letras Iberoamericanas de la Universidad Nacional Autónoma de México y Doctor en Letras Hispánicas del Colegio de México. Ha sido Premio Nacional de Periodismo Simón Bolívar. Actualmente es editor de la revista Aguaita, del Observatorio del Caribe Colombiano, así como coordinador de la Cátedra del Caribe Colombiano del mismo instituto.
} 
Me explico: el "ejercicio del criterio", en nuestra región y en nuestro país, cuando logra superar la superficialidad del impresionismo amateur deriva con frecuencia en la acumulación inescrupulosa de intimidades biográficas, en las tautologías tristes de una sociología vulgar, aunque bien intencionada, o en los arduos catálogos de una semiótica mal calcada. Con la excepción de Rafael Gutiérrez Girardot, muy rara es la crítica literaria con fundamentos filosóficos. Tal es la primera sorpresa, entre las varias, que nos depara este libro, atento, sin pereza, a la exploración de las incitaciones del texto -las alusiones, las citas, las reminiscencias, las resonancias- y a su inserción en el vasto, infinito sistema de la literatura.

Juego de espejos enfrentados, los ensayos de Santos nos proporcionan las claves de su arte crítica, que privilegia ciertos temas y motivos, en particular, "la agonía y la absurda épica del individuo", "la vertiginosa batalla del 'yo' para siempre solitario", el tiempo, la desolación de la modernidad, con los estragos de la urbe, la destrucción, la caída del hombre, su alejamiento del ángel, la pérdida del paraíso y sus consecuencias, la soledad, la exacerbación de los sentidos que reafirma su ser en el mundo y sirve de consuelo frente a la magnitud de la derrota, "los arquetipos recurrentes en la primordial memoria de los hombres" y "el pasado mítico del alma".

Para Santos, con apoyo en la sabiduría de Rojas Herazo, el descifre de la poesía -una forma de la misma- debería conducir al silencio original, al vacío previo a la palabra donde se concentra el universo en un instante y fluyen de manera simultánea las múltiples posibilidades significativas de la realidad. El crítico que, a diferencia del poeta, no parte de "la virginidad del silencio", sino de la materialidad del lenguaje, con base en una experiencia epifánica debe "despertar oscuras reminiscencias" que desplieguen la autonomía estética de la palabra: las "catedrales de la imaginación".

Santos selecciona seis autores (tres de la vanguardia cosmopolita, uno de la transculturadora y dos de la posvanguardia; dos hispanoamericanos y cuatro caribeños), de alta imaginación y honda meditación -José Félix Fuenmayor, Héctor Rojas Herazo, Vicente Huidobro, Jorge Luis Borges, Alejo Carpentier y Maryse Condé-, y a partir de sus obras más significativas empieza a tejer un diálogo pleno de irradiaciones tanto cordiales como críticas entre las mismas, que no sólo nos revela matices inesperados, sino asimismo una sorprendente fraternidad entre ellas, en cuanto a travesías que nos hablan del cuestionamiento o la reinvención de las utopías y de la fuerza fabuladora de la palabra como camino de regreso al paraíso a través de cartografías imaginarias. 
Además de la singular selección de los autores, todos de elegante escritura, fino escepticismo y vocación transgresora -quienes, ajenos a la epistemología tradicional y al realismo ramplón, y conscientes del relativismo del logos occidental, aspiran a los fulgores de la ficción-, cabe destacar algunas virtudes del trabajo de Santos. Mencionaré tres. En primer lugar, su bagaje literario, en el que sobresale la presencia copiosa de autores universales fuertes desde los de corte clásico (de Homero a Goethe, pasando por Dante, Petrarca y Cervantes), hasta los románticos alemanes e ingleses y unos selectos contemporáneos (Baudelaire, Rilke, Camus y Yourcenar); en segundo lugar, su aguda mirada crítica en la que se integran las certezas e incertidumbres de los filósofos (Platón, Nietzsche, Cassirer, Foucalt y Cioran, entre otros), con las tendencias modernas de la crítica (Durand, Genette, Bajtín, Barthes, Benjamin, Borges, Bourdieu y Bloom). Y por último, la frescura de su lenguaje, que ejerce con el lector la cortesía de la claridad al tiempo que alcanza, por momentos, niveles de creatividad, sin perder su norte exegético.

El resultado es el enriquecimiento de las obras, en particular las del Caribe colombiano (las de Fuenmayor y Rojas Herazo), las cuales resurgen plenas de resonancias filosóficas, estéticas, mitológicas y literarias. Sirven de ejemplo tanto las conexiones que Santos postula entre la novela Cosme, de José Félix Fuenmayor, y la estética neoplatónica del dulce estilo nuevo, la narrativa de Cervantes, Voltaire y Sade, la poesía romántica y el existencialismo de Camus, o las afinidades entre la poesía de Rojas Herazo y la de Huidobro, y sus conexiones con los mitos bíblicos y griegos, las letanías de Baudelaire y las reflexiones de Tomás de Aquino y Cioran. Celebro, pues, esta nueva voz en el firmamento de nuestra crítica en el que se van perfilando miradas y escrituras nuevas encaminadas a cerrar el abismo secular entre nuestra producción literaria y su recepción crítica. 
